\title{
The Quantum Mechanism of Earthquakes as Exemplified by a Sudden Ejection of Rocks and Gas from a Rock Mass during the Process of a Coulomb Explosion
}

\author{
Serguei Bychkov ( $\sim$ serguei58@rambler.ru ) \\ University of British Columbia
}

Article

Keywords: quantum, photon, electron, earthquake, chemical chain reaction (CCR)

Posted Date: October 12th, 2020

DOI: https://doi.org/10.21203/rs.3.rs-87807/v1

License: (9) This work is licensed under a Creative Commons Attribution 4.0 International License.

Read Full License 


\section{Abstract}

At the moment, there are several hypotheses in geophysics that explain especially dangerous processes of the earth's crust movements - sudden outbursts of rocks and gas from a rock mass from the point of view of classical physics. Despite the fact that various macroscopic systems can be accurately described using classical mechanics and electrodynamics, a real mechanism and a working model of this phenomenon cannot be built. Consequently, to develop a model of sudden outbursts of rocks and gas, it is necessary to apply new approaches and methods, different from the description of macroscopic systems. This article describes a quantum version of the process of the ejection of rocks from a rock mass. In particular, we described the mechanism of the Coulomb explosion that occurs in the rocks of the earth's crust with a sharp change in rock pressure and built a model of the sudden release of rocks and gases. In our opinion, the quantum processes described by us can be sources not only of sudden outbursts and rockslide but also sources of more formidable phenomena - earthquakes and volcanic explosions.

\section{Introduction}

It is known that depending on the type of atomic particles located in the nodes of the crystal lattices, and the nature of the bond between the particles, there are four types of lattices: ionic, atomic, molecular, and metallic. It is known that the rocks of the earth's crust contain almost no pure substances, i.e. Rocks are a composite of many elements, which means that any rock can contain an ensemble of various types of crystal lattices, randomly located throughout the volume of rocks in the form of mineral inclusions. It is known that the crystal lattice can explode due to the destruction of bonds between atomic particles in accordance with the mechanism of the Coulomb explosion, which consists in the fact that between the atomic particles located in the nodes of the crystal lattice there are Coulomb repulsive forces, which are compensated by the electrons in the volume of the lattice. It is known that in the case of the removal of a part of electrons from the lattice volume, the Coulomb destruction of bonds between the particles occurs and the crystal lattices instantly explode with the release of energy. It is known that the process of a Coulomb explosion takes $\geq 10^{-9} \mathrm{~s}$. Consider the classic examples of the Coulomb explosion described in the scientific literature. Chemical Coulomb explosion. Until now, the scientific world knew and firmly believed that the explosion of sodium in water occurs due to its active reaction with water, during which a large amount of heat and molecular hydrogen $2 \mathrm{Na}+2 \mathrm{H}_{2} \mathrm{O}=2 \mathrm{NaOH}+\mathrm{H}_{2} \uparrow$ is released, which leads to the formation and explosion oxyhydrogen gas $2 \mathrm{H}_{2}+\mathrm{O}_{2}=2 \mathrm{H}_{2} \mathrm{O}$. And suddenly, in 2015, a group of Czech scientists discovered that this was not true! As scientists have shown during experiments [1] recorded on a high-speed camera, when sodium is immersed in water, there is an immediate exit of electrons from the metal surface. As a result of the process, an electron deficiency arises in the lattices of sodium molecules. As a result, the Coulomb repulsive forces of ions begin to prevail, which leads to the explosion of the lattice with the release of the explosion energy. Mechanical Coulomb explosion. In this type of Coulomb explosion, the atoms-ions of the nodes of the crystal lattice are bound by free electrons, which move inside it in a random manner, reminiscent of the movement of an electron gas. It was shown in $[2,3]$ 
that if free electrons are "distracted" from the role of "glue" by increasing the energy of the electron flow, this will lead to the escape of electrons from the crystal lattice and its explosion. The increase in the energy of the electron flow can be achieved in several ways: 1. Due to the inertial forces of electrons. A striking example of such a case is the sharp deceleration of a modern high-speed projectile when it hits the armor of a tank and the appearance at this moment of the inertial force of electrons, which continue to move and, due to the inertial forces that have arisen, fly out of the crystal lattice. A Coulomb projectile explosion occurs, the energy of which burns through the tank's armor. The fact that the inertial process of the Coulomb explosion is real was shown by the famous experiment with a coil of copper wire conducted by the American scientists Tolman and Stewart (Tolman R. C., Stewart T. D.) back in 1916. 2. Due to the forces of electromagnetic nature, when a high-density electric current is passed through a substance or irradiated with a high energy laser beam. It is known that the current density is proportional to the electron flow velocity, and the kinetic energy is proportional to the square of the velocity. Consequently, if the current density is increased by a factor of a thousand, the kinetic energy of the electron flow will increase by a factor of one million and they will unanimously leave the crystal lattice, which will naturally lead to a Coulomb explosion. At the moment, there are several patents for "Method of the explosion of solid metal using electrical force," for example, RU2145147C1 [4].

\section{Theoretical Part}

Below we give examples of sudden outbursts of rocks and gas from a rock mass from which it can be concluded that nature uses both chemical and mechanical, and combined mechanisms of the Coulomb explosion in the processes of emissions. A common feature of Coulomb explosions is the release of a byproduct - a large amount of ultrafine dust, the so-called rabid flour (up to $40 \%$ of the total mass of the ejection), with particle sizes within a few nanometers, which can be formed during the ejection of rocks and gas only in a single case - as a result of the destruction of crystal lattices [5], because such a fine grinding of the rock cannot be achieved by any kind of blasting or without special equipment. The formation of a gaseous phase during the processes of sudden outbursts of rocks is also a by-product of the process, which makes an additional contribution to the energy characteristic of the Coulomb explosion. The gaseous phase is formed for two reasons: 1 . In chemical reactions of the type of formation of hydrogen molecules during the reaction of sodium in water. For example, due to hydroxide ions in the crystal lattices of hydroxides and basic salts. 2. As a result of dissociation and ionization of molecules of a solid solution of gases formed in the crystal lattices of rocks at the moment of formation of the rock mass and passing into a free state in the focus of the Coulomb explosion due to the emerging chemical chain reaction (CCR). The chain nature of the reaction is caused by the appearance of accelerated electrons, which are not only the source of the Coulomb explosion but also the initiator of the CCR and which in turn will cause the appearance of intermediate active particles (free radicals, excited atoms, and molecules) $[6,7,8]$. It should be noted that the formation of the gaseous phase and the passage of the shock wave of the Coulomb explosion cause another physical phenomenon in the rock mass, which is especially pronounced during underground emissions - the Richtmyer - Meshkov instability [9], which results in a sudden outflow of turbulent gas jets from the rock mass and the 
destroyed particles of rocks captured by them from the point of origin of the disturbance following the front of the shock wave.

Quantum rock and gas ejection mechanism

During the formation of an elementary rock mass, as a result of the action of high temperatures, pressure, an aggressive environment, and the stresses arising from the movement of rock blocks, metamorphic transformations of the mass occur. Over time, the rock massifs not only change the geological, geometric, and chemical form and structure, but also energy parameters. As a result of the compaction of rocks (a change in its volume), as well as from the effect of high temperatures, energy in the form of quanta is imparted to the electrons of the rocks. According to Mr. Bohr's quant model of the atom, if the energy imparted to the electron exceeds the critical potential, then the electron goes to a higher level, storing potential energy (a macroscopic analogy is a compressed spring). A mountain range in such a metastable state can remain indefinitely. Over the years, at a random moment in time, as a result of the confluence of various natural or man-made factors, there is a sharp decrease in rock pressure in the considered elementary volume of the rock mass. In this case, the rock mass changes its volume and shape in the form of rock heaving (analogy - the spring is unclenched) and as a result, its potential energy sharply decreases, and the kinetic energy, and therefore the speed of electrons, atoms, and molecules, increases sharply, which leads to their mutual inelastic collision of the second kind, the appearance of electric charges and the appearance of an electromagnetic field. In this process, it is especially important that in inelastic collisions of the second kind, electrons do not emit quanta, but on the contrary, energy is transferred from excited atoms and molecules to electrons. As a result, electrons are accelerated and leave the crystal lattice, simultaneously initiating two processes - the Coulomb explosion and the CCR. There are two things to note here. 1. The first nuance is associated with the behavior of hydrated water molecules. In the generated electromagnetic field, the $\mathrm{H}_{2} \mathrm{O}$ molecules create a hydration shell around the ions of the crystal lattice, which screens the ions from charges of the opposite sign. And since water, depending on the temperature, has a high dielectric constant of $\sim 80$, the electrostatic attraction of ions and electrons will accordingly decrease $\sim 80$ times. It should be noted that many rocks of the lithosphere contain hydroxide mineral impurities containing hydrated water: $\left[\left(\mathrm{SiO}_{2}, \mathrm{Al}_{2} \mathrm{O}_{3}, \mathrm{TiO}_{2}, \mathrm{Fe}_{2} \mathrm{O}_{3}, \mathrm{CaO}, \mathrm{MgO}, \mathrm{K}_{2} \mathrm{O}\right.\right.$, $\left.\mathrm{Na}_{2} \mathrm{O}\right) \cdot \mathrm{nH}_{2} \mathrm{O}$. For example, the mineral constituent of marble limonite $-\mathrm{Fe}_{2} \mathrm{O}_{3} \cdot \mathrm{nH}_{2} \mathrm{O}$, is also the mineral constituent of coal and many other rocks. In connection with the leading role of the dielectric constant in the ejection processes, it should be noted the class of so-called ferroelectrics, which can also be part of rocks, for example, the constant of the dielectric constant of tetrahydrate of double sodium-potassium salt $\mathrm{KNaC}_{4} \mathrm{H}_{4} \mathrm{O}_{6} 4 \mathrm{H}_{2} \mathrm{O}$ is much higher than water and is $\sim 500$. 2. The second nuance lies in the fact that the nucleation of chains occurs with the participation of numerous admixtures-initiators, which are rich in rocks. Such impurities can be molecules with a weak bond, for example, alkali metals, during the decomposition of which free radicals are easily formed, or molecules that easily enter into redox reactions. For example, coal ash, depending on the grade, contains: $1.3-80.9 \% \mathrm{Fe}_{2} \mathrm{O}_{3} ; 0.87-42.7 \% \mathrm{Al}_{2} \mathrm{O}_{3}$; $1.7-76 \% \mathrm{SiO}_{2} ; 0.6-36.9 \% \mathrm{CaO} ; 0-10.7 \% \mathrm{SO}_{3}$. In addition, small amounts of lithium, potassium, sodium, magnesium, rubidium, cesium, sulfur, phosphorus, sometimes titanium, zinc, copper, nickel, etc. are 
included in the composition of coal, which can act as initiators of the CCR. Consider a few examples of sudden rock and gas outbursts.

The Usoi collapse [10] that occurred in the Pamirs on 02/18/1911., Fig. 1, can be considered a sudden release of rocks and gas, because a block of rock with a volume of $\sim 1.5 \mathrm{~km}^{3}$, after being torn away from the parent body, did not just slide down the slope, but flew a distance of $5 \mathrm{~km}$. along an inclined path. The calculated energy and momentum of force for the movement of a physical body of such a mass is $1.1 \times$ $10^{17} \mathrm{~J}$. To date, there is no reasonable explanation for this well-described and documented case in the scientific literature, however, as well as other similar catastrophic collapses. We believe that the Usoi collapse occurred due to the Coulomb explosion that occurred at the time of a sharp change in the cantilever loads in the mother's body when various natural mining-hydro-geological and weather factors coincided in time. It is known that the displaced mass of the ejection consisted of siliceous shale, and the bed of the ejection funnel was lined with reddish marble. According to our hypothesis, as a result of a combination of various factors, the cantilever loads exceeded the ultimate strength of the rocks in the zone of contact between siliceous shale and marble. A sudden redistribution of loads led to the appearance of accelerated electrons in the array, which, having received energy from excited atoms and molecules and the energy of inertial forces at the moment of acceleration, were forced to leave the crystal lattice. The electromagnetic field induced by the moving stream of electrons unfolded the dipoles of the hydrated water of the marble, which isolated the ions of the crystal lattice and compensated for the Coulomb forces of attraction between the ions and electrons by the value of the constant of dielectric permeability, which gave rise to the reactions of the Coulomb explosion and CCR. The resulting impulse of force with an energy of $1.1 \cdot 10^{17} \mathrm{~J}$. threw a part of the mountain range with a volume of $1.5 \mathrm{~km}^{3}$ at a distance of $5 \mathrm{~km}$. The resulting gases scattered in the atmosphere. The collapse zone was covered with a layer of rabid flour, the deposits of which can be traced to the present day. In addition, the researchers found melted pieces of rocks, which in no way fit into the gravitational hypothesis of collapse. Our hypothesis assumes that the fused rocks serve as strong evidence of the high-speed process of the Coulomb explosion that occurred, accompanied by the release of a significant level of thermal energy, which the massif did not have time to take away and that served as an impetus for further heating of rocks and gases in geometric progression and for the even greater acceleration of reactions due to shock ionization. A month ago, a similar incident occurred in the vicinity of Toronto, Canada, and was accompanied by the sound of a strong explosion and a thick cloud of rabid flour [11]. True, the caliber of this emission was much smaller.

Sudden rock and gas outbursts in underground potash and coal mines

From the experience of underground mines for the extraction of potash salts and coal, it can be concluded that the amount of rock and gas emissions increases with the depth of mining, that is, with an increase in rock pressure. Let us give an example of a classic discharge that occurred on June 7, 1953, at the Menzengraben mine (Germany). At the time of the release, several hundred thousand cubic meters of gas were released and about 100,000 tons of salt were emitted. The gas mixture consisted of CO2 (up to $95 \%$ ) and N2. Gas escaped noisily from both shaft shafts $520 \mathrm{~m}$ deep for about 25 minutes. The blowout 
completely disrupted ventilation, destroyed the mining equipment, the reinforced concrete roof of the mine shaft [12]. Based on the consideration of the conditions of the Coulomb explosion, we can conclude that the mined potassium salt - carnallite $\mathrm{KCl} \cdot \mathrm{MgCl}_{2} \cdot 6 \mathrm{H}_{2} \mathrm{O}$, ideally meets the requirements of the initiator of the Coulomb explosion and CCR. Carnallite is an aqueous potassium chloride, which is no less aggressive metal than sodium, which has hydrated water molecules in its composition. In addition, the mineral carnallite includes impurities of other, no less aggressive alkali metals - rubidium and cesium, which, in turn, can act not only as initiators of the Coulomb explosion but also as catalysts for CCR. And the last, no less important point, a sudden release occurred at the time of blasting, that is, at the time of a sharp drop in rock pressure in the massif. In this case, an ideal case of a merger of chemical and physical and mechanical factors occurred, which led to a powerful ejection of rocks from the massif, which ended in a gas ejection as a result of the Richtmyer-Meshkov instability. According to the same scheme, sudden rock and gas outbursts occur in coal mines, but since coal contains much less alkali metal impurities in its composition, the process of coal sudden rock and gas outbursts is extended over time. Initially, several local mini-Coulomb explosions occur, which accompany the CCR of insignificant strength. In the process of "swinging," more and more atoms and electrons are drawn into the ejection process. In the rock mass, noise effects, increased gas release, firing of the rock with pieces of coal, peeling of the face and sides of the mine start, and only after such "swinging" a full-fledged release of rocks and gas occurs. Although, sudden rock and gas outbursts of significant strength can occur immediately, without "swinging". With the largest emissions, millions of $\mathrm{m}^{3}$ of gas were released and emitted tens of thousands of tons of coal.

\section{Conclusion}

The ordinariness of the process of the Coulomb explosion, convincingly demonstrated in the reaction of sodium in water, destroyed the myth of the Coulomb explosion as a process capable of proceeding only at high energy costs and parameters, at high $\mathrm{P}, \mathrm{T}$ and only in special cases, supposedly unattainable under normal conditions of existence of matter ... Based on the above examples, we have shown the possibility of a Coulomb explosion in the rocks of the earth's crust. Moreover, we argue that earthquakes and volcanic explosions occur according to the same scenario since the rocks of tectonic plates - granites and basalts contain oxides and mineral admixtures of alkali metals, hydrated water, and high variable loads of tectonic plates at high temperatures of rocks contribute to entrainment of large volumes of material into the process, which leads to the release of huge amounts of seismic energy

\section{References}

1. Mason P.E. Uhig F. Vaněk V. et al. Coulomb explosion during the early stages of the reaction of alkali metals with water, Nature Chemistry01.2015 https://www.nature.com/articles/nchem.2161

2. Марахтанов Марахтанов A. Coulomb explosion of metal. The scientific journal Science and Life \#4 2002 https://www.nkj.ru/archive/articles/4072/

3. Yavorsky V.V. Energy from nowhere. The scientific journal Science and Life \#10 1988

4. Patent for invention RU2145147C1 https://elibrary.ru/item.asp?id=37847031 
5. Bulat A.F. Dyrda V.I. Sudden emissions coal and gas in the context nonlinear nonequilibrium thermodynamics. Scientific journal Coal of Ukraine. December 2013 file:///C:/Users/S/Downloads/ugukr_2013_12_6.pdf

6. https://xumuk.ru/encyklopedia/2/5139.html

7. Bychkov S.V. Chemical reactions during earthquakes. An explosion of the rock mass as a source of tremors, sudden emissions, and rock bursts. Bulletin of the Scientific Center for the Safety of Work in the Coal Industry. 2016. No. 4. S. 38-47. https://cyberleninka.ru/article/n/himicheskie-reaktsii-vprotsesse-zemletryaseniy-vzryv-porod-gornogo-massiva-kak-istochnik-tolchkov-vnezapnyh-vybrosovi-gornyh-udarov

8. Sevenov N.N. Some Problems Relating to Chain Reactions and to the Theory of Combustion. Nobel Lecture, December 11, 1956 https://www.nobelprize.org/uploads/2018/06/semenov-lecture.pdf

9. OrtegaL. Barton P.T.D. I. Pullin D.I. Meiron D.I. Richtmyer-Meshkov Instability at Solid-Gas Interfaces. 29th International Symposium on Shock Waves 2p. 1131-1136 https://link.springer.com/chapter/10.1007/978-3-319-16838-8_54

10. Vaskov I.M. Large-scale landslides: geodynamics and forecas / Vladikavkaz 2019. http://www.skgmi-gtu.ru/Portals/0/_Monographs/2266-\%D0\%BC.pdf?ver=2019-02-13-162736-707

11. https://www.cbc.ca/news/canada/toronto/large-portion-scarborough-bluffs-collapse-1.5697143

12. Laptev B.V. Historiography of development accidents salt deposits. Scientific journal Labor Safety in Industry \#12, 2011 https://www.safety.ru/sites/default/files/2011-12-41-46.pdf

\section{Figures}

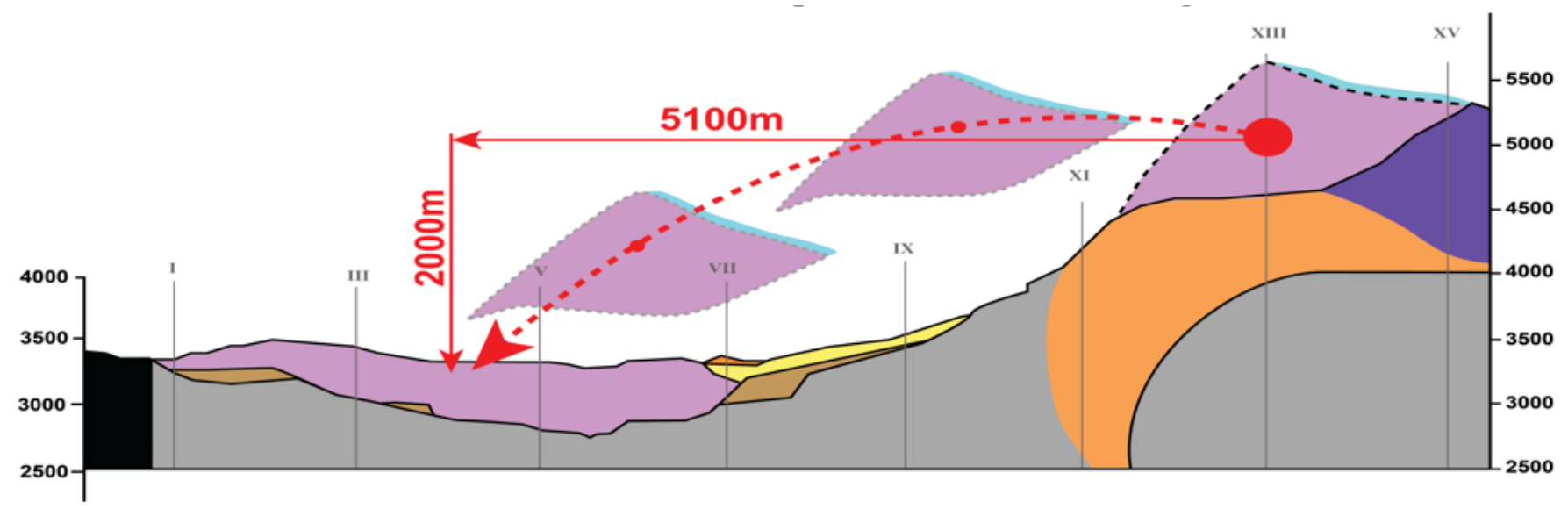

Figure 1

Usoy landslide [10] page 280 